\title{
Sperm whale presence observed using passive acoustic monitoring from gliders of opportunity
}

\author{
Pierre Cauchy ${ }^{1,2, *}$, Karen J. Heywood ${ }^{1}$, Denise Risch ${ }^{3}$, Nathan D. Merchant ${ }^{2}$, \\ Bastien Y. Queste ${ }^{1,4}$, Pierre Testor ${ }^{5}$ \\ ${ }^{1}$ Centre for Ocean and Atmospheric Sciences, School of Environmental Sciences, University of East Anglia, \\ Norwich NR4 7TJ, UK \\ ${ }^{2}$ Centre for Environment, Fisheries \& Aquaculture Science (Cefas), Lowestoft NR33 0HT, UK \\ ${ }^{3}$ Scottish Association for Marine Science, Scottish Marine Institute, Oban, Argyll PA37 1QA, UK \\ ${ }^{4}$ Department of Marine Sciences, University of Gothenburg (UGOT), 40530 Gothenburg, Sweden \\ ${ }^{5}$ CNRS-Sorbonne Universités (UPMC Univ. Pierre et Marie Curie, Paris 06)-CNRS-IRD-MNHN, UMR 7159, \\ Laboratoire d'Océanographie et de Climatologie (LOCEAN), Institut Pierre Simon Laplace (IPSL), Observatoire Ecce Terra, \\ 75005 Paris, France
}

\begin{abstract}
Habitat use by the endangered Mediterranean sperm whale subpopulation remains poorly understood, especially in winter. The sustained presence of oceanographic autonomous underwater vehicles in the area presents an opportunity to improve observation effort, enabling collection of valuable sperm whale distribution data, which may be crucial to their conservation. Passive acoustic monitoring loggers were deployed on vertically profiling oceanographic gliders surveying the north-western Mediterranean Sea during winter 2012-2013 and June 2014. Sperm whale echolocation 'usual click' trains, characteristic of foraging activity, were detected and classified from the recordings, providing information about the presence of sperm whales along the glider tracks. Widespread presence of sperm whales in the north-western Mediterranean Sea was confirmed. Winter observations suggest different foraging strategies between the Ligurian Sea, where mobile and scattered individuals forage at all times of day, and the Gulf of Lion, where larger aggregations target intense oceanographic features in the open ocean such as fronts and mixing events, with reduced acoustic presence at dawn. This study demonstrates the ability to successfully observe sperm whale behaviour from passive acoustic monitoring gliders. We identified possible mission design changes to optimize data collected from passive acoustic monitoring glider surveys and significantly improve sperm whale population monitoring and habitat use.
\end{abstract}

KEY WORDS: Passive acoustic monitoring - PAM - Glider - Autonomous underwater vehicle · Habitat use $\cdot$ Mediterranean Sea $\cdot$ Sperm whale $\cdot$ Physeter macrocephalus

\section{INTRODUCTION}

Sperm whales Physeter macrocephalus are widespread across the Mediterranean Sea (Drouot et al. 2004c, Frantzis et al. 2011, Carpinelli et al. 2014, Lewis et al. 2018) and constitute an isolated subpopulation, genetically distinct from the Atlantic population (Drouot et al. 2004a, Engelhaupt et al. 2009). The Mediterranean sperm whale subpopulation contains fewer than 2500 mature individuals (Notarbartolo-

*Corresponding author: p.cauchy@uea.ac.uk
Di-Sciara 2014) and is considered Endangered by the IUCN (Notarbartolo di Sciara et al. 2012). Anthropogenic pressures on this subpopulation include bycatch in fishing gear (Notarbartolo di Sciara 1990, Notarbartolo di Sciara et al. 2004), ship strike (Carrillo \& Ritter 2010, Frantzis et al. 2019), ingestion of marine debris (de Stephanis et al. 2013) and anthropogenic noise disturbance (Frantzis et al. 2003, Weir 2008) and whale-watching activities (Gordon et al. 1992, Notarbartolo-di-Sciara et al. 2008). Sperm whale

(C) The authors 2020. Open Access under Creative Commons by Attribution Licence. Use, distribution and reproduction are unrestricted. Authors and original publication must be credited. 
distribution in the Mediterranean Sea is non-uniform (Gannier et al. 2002, Boisseau et al. 2010) and influenced by oceanographic (e.g. fronts, upwellings, primary production) and topographic features (e.g. steep slopes, sea mounts) (Cañadas et al. 2002, Praca et al. 2009, Frantzis et al. 2014, Pirotta et al. 2019, Virgili et al. 2019). Information on the ecology of the Mediterranean sperm whale subpopulation remains sparse and does not meet the needs of conservation managers and policy makers (Pace et al. 2014). Broader surveys are required, particularly with increased observational effort in non-summer months (Mannocci et al. 2018), to better understand the seasonality of sperm whale habitat use and identify key seasonal habitats, which will allow for appropriate management of shipping and fishing activities (Rendell \& Frantzis 2016).

Sperm whales are highly vocal, producing 4 distinct types of clicks both for echolocation and social interaction. When socializing at the surface, they use short stereotyped sequences of clicks, called 'codas', to maintain cohesion in a group (Weilgart \& Whitehead 1993), and mature male sperm whales produce 'slow clicks' of lower frequency and longer inter-click intervals (Weilgart \& Whitehead 1988). When foraging, they produce extremely powerful and highly directional 'usual clicks' (Møhl et al. 2000, Wahlberg 2002, Zimmer et al. 2005), punctuated by lower intensity and shorter inter-click interval 'creak clicks' during prey capture (Madsen et al. 2002, Miller et al. 2004). Sperm whales spend a substantial amount of their time foraging. While in a foraging cycle, they produce usual clicks $60 \%$ of the time (Watwood et al. 2006, André et al. 2017), starting at a depth of 100$200 \mathrm{~m}$ at the beginning of the dive until the beginning of the ascent phase (Madsen et al. 2002, Watwood et al. 2006). Usual clicks are emitted in series of 10 s to 100 s (Wahlberg 2002), in a $10 \mathrm{~Hz}-30 \mathrm{kHz}$ frequency band with an inter-click interval varying from 0.5-2 s (Madsen et al. 2002, Møhl et al. 2003). Usual clicks provide a reliable indicator of sperm whale presence and foraging activity (Whitehead 2003, Stanistreet et al. 2018), and their specific features allow the whales to be identified and detected from a distance of 4-20 km (Gannier et al. 2002, Barlow \& Taylor 2005, André et al. 2017, Miller \& Miller 2018).

Passive acoustic survey methods have significantly improved over recent decades and are now commonly used in cetacean observation (Pavan et al. 2008, Samaran et al. 2010, Au et al. 2014, Caruso et al. 2015). Unlike more traditional visual survey methods, passive acoustic techniques offer sustained observations during nighttime and adverse weather conditions (Barlow \& Taylor 2005, Mellinger 2007, Van Parijs et al. 2009) and when the whales are below the surface. In the case of sperm whales, which are highly vocal and deep divers, combined visual and acoustic surveys have revealed that acoustic techniques are much more efficient than visual techniques, as sperm whales are always first detected acoustically (Boisseau et al. 2010).

Ocean gliders are autonomous underwater vehicles, carrying various payloads to monitor the ocean. They provide high resolution $(\sim 2 \mathrm{~h}, \sim 2 \mathrm{~km})$ hydrographic profiles (Testor et al. 2010, Rudnick 2016), performing long autonomous missions (several months to $1 \mathrm{yr}$, and several thousand $\mathrm{km}$ ) unaffected by extreme weather events. They are highly suitable for passive acoustic monitoring (PAM), gliding quietly, unpropelled, through the water and collecting information on the acoustic properties of the water column. PAM sensors have been successfully deployed on ocean gliders for weather observation (Cazau et al. 2018, Cauchy et al. 2018) and for cetacean monitoring (Moore et al. 2007, Baumgartner \& Fratantoni 2008, Klinck et al. 2012, Baumgartner et al. 2013).

This paper presents a case study on the ability to use PAM glider observations as a tool to study sperm whale habitat use. We added PAM sensors to oceanographic gliders deployed in the north-western Mediterranean Sea during winter 2012-2013 in the framework of the DEWEX experiment (Testor et al. 2018) and summer 2014 within the REP14-MED experiment (Onken et al. 2018), recording a total of 5 mo of acoustic data along $3200 \mathrm{~km}$ of glider tracks. We focussed on the detection of sperm whale usual clicks to monitor the presence of whales along the glider tracks. We identified 39 distinct encounter events with one or more sperm whales, along the slopes and in the open ocean, in the Ligurian Sea, the Sea of Sardinia and the Gulf of Lion.

\section{MATERIALS AND METHODS}

\subsection{Instrumentation and field operations}

The platforms used in this study were the Slocum glider, developed by Teledyne Webb Research, and the Seaglider, developed by the University of Washington and distributed by Kongsberg. These devices are autonomous underwater vehicles driven by buoyancy changes, controlled by pumping oil into and out of a swim bladder, which induces vertical motion in the water column from the surface down to $1000 \mathrm{~m}$ depth. Fixed wings convert vertical velocity 
into forward velocity. Internal battery displacements enable pitch and roll management for direction changes. This novel way of propulsion - performing successive V-shape dives along a pre-defined trajectory - makes it a very quiet platform between the oil pumping phases that occur during bottom and surface inflexions of each dive (every $\sim 2 \mathrm{~h}$ for $1000 \mathrm{~m}$ dives). The gliders were able to cover $\sim 20 \mathrm{~km} \mathrm{~d}^{-1}$ for up to 6 mo. Along with the PAM sensor, the gliders were typically equipped with integrated temperature, salinity, pressure, oxygen, turbidity and chlorophyll fluorescence sensors.

The Slocum gliders were equipped with an externally mounted Acousonde B003A-HF data logger, developed by Greenridge Sciences (Fig. 1). The Acousonde is a self-contained underwater acoustic recorder comprising 2 hydrophones, sensors for attitude, orientation, depth and temperature, a digital recorder and a field-replaceable battery (Burgess 2010). The core of the sensor consisted of a high frequency hydrophone (capable of sampling up to

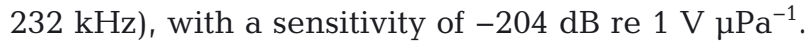
A 6 pole linear-phase anti-aliasing filter was used, with $-3 \mathrm{~dB}$ passband $(12.5-42 \mathrm{kHz})$ and $-22 \mathrm{~dB}$ at $100 \mathrm{kHz}$ (Fig. S1a in the Supplement at www. int-res.com/articles/suppl/n042p133_supp.pdf). Data were stored on a 128 GB flash memory, with a 16 bit sampling resolution. An external 3D-cell tethered battery pack allowed up to $200 \mathrm{~h}$ of recording. The Acousonde operated autonomously and had its own battery, memory and programmed mission. Data processing was undertaken after the sensor was recovered. Initially developed to be attached to marine mammals (Cazau et al. 2017), it has also been used on ocean gliders in previous studies (Nott 2015, Cauchy et al. 2018).

The Seaglider was equipped with an integrated Seaglider PAM system (Fig. 1). The acoustic data logger consisted of an HTI-92-WB hydrophone (High Tech) with a sensitivity of $-165 \mathrm{~dB}$ re $1{\mathrm{~V} \mu \mathrm{Pa}^{-1}}^{-1}$ associated with a WISPR v.1.1 digital signal processing board with an Analog Devices BF537E Blackfin CPU and HM1 digital preamplifier (Embedded Ocean Systems). The frequency response of the preamplifier board was designed to be approximately equal to the inverse of typical deep-water ambient noise (Matsumoto et al. 2015) (Fig. S1b). The sampling frequency was fixed at $125 \mathrm{kHz}$, and the data were stored on a 512 GB flash memory, with a 24 bit maximum sampling resolution.

The glider missions took place in the north-western Mediterranean basin. The PAM-equipped Slocum gliders were deployed within the frameworks of the Mediterranean Ocean Observing System for the Environment (MOOSE; www.moose-network.fr) and the Deep Water Experiment (DEWEX) (Testor

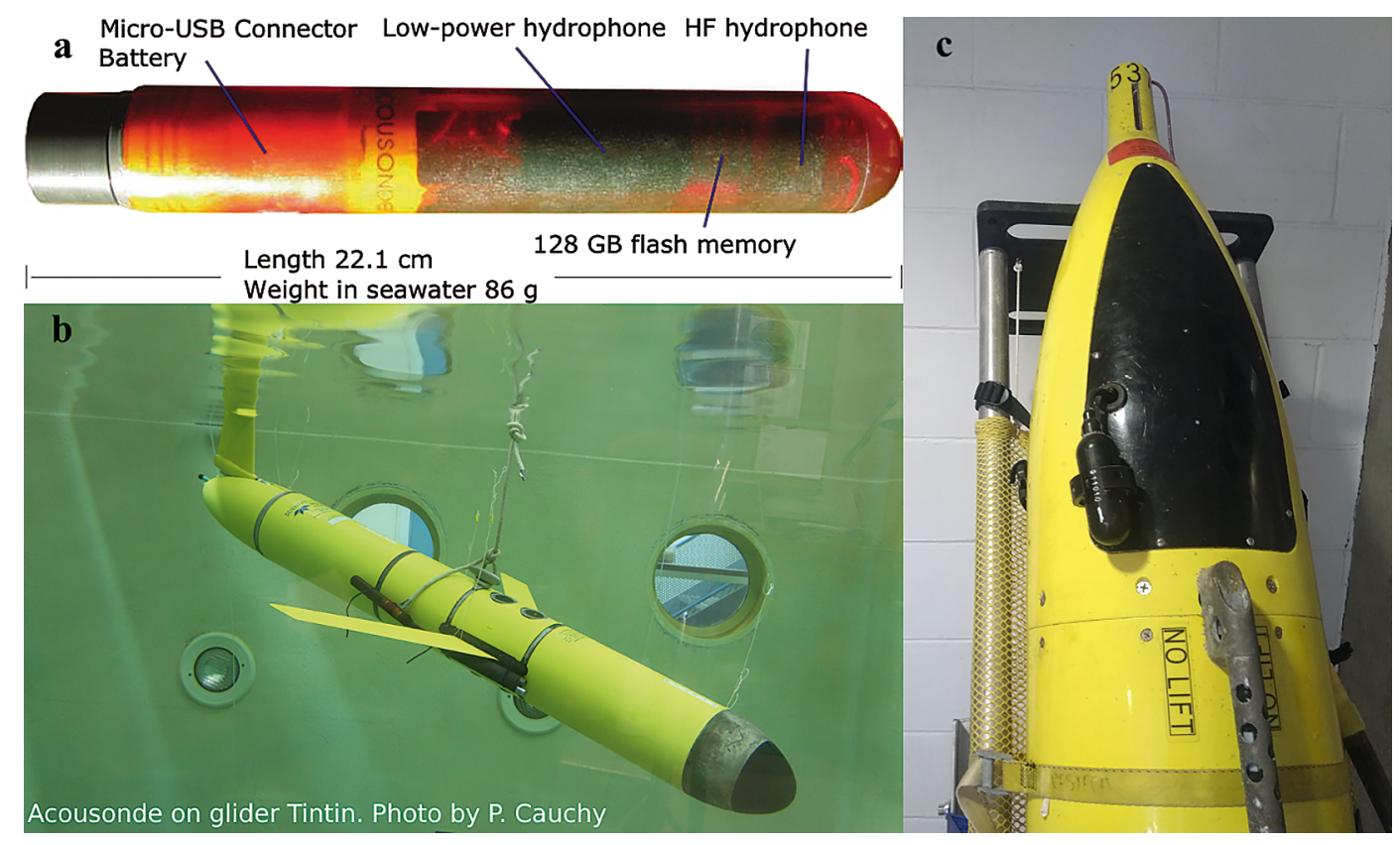

Fig. 1. (a) Internal layout of the Acousonde ${ }^{\mathrm{TM}}$ data logger and (b) experimental setup, externally attached on a Slocum glider in the ballasting tank. (c) Seaglider integrated passive acoustic monitoring unit. Only the sensor can be seen outside the hull; the electronics are integrated inside the glider's pressure housing 
et al. 2018). MOOSE offers year-long coverage of repeated sections of the north-western Mediterranean basin, monitoring oceanographic variability over a continuum of spatial and temporal scales to assess the evolution of oceanic circulation and anthropogenic impacts. DEWEX was targeted at better understanding the dynamics of the vernal bloom that occurs in this region after deep convection events in winter. The Slocum glider 'Tintin' was deployed twice in the middle of the Pelagos Sanctuary, a Marine Protected Area created to protect marine mammals (Notarbartolo-di-Sciara et al. 2008). It followed a predefined transect crossing the Ligurian Sea (Table 1, Fig. 2). The Slocum glider 'Hannon' was deployed twice along a predefined transect covering the open ocean across the Gulf of Lion and the westernmost slopes of the basin (Table 1, Fig. 2). Each of these transects included a mooring site, DYFAMED/Azur $\left(43.39^{\circ} \mathrm{N}\right.$, $\left.7.84^{\circ} \mathrm{E}\right)$ and $\operatorname{LION}\left(42.06^{\circ} \mathrm{N}, 4.64^{\circ} \mathrm{E}\right)$, respectively, with the permanent presence of a meteorological buoy and a mooring line equipped with oceanographic sensors at several depths. For consistency, these transects will be called Gulf of Lion (glider missions GoL1 and GoL2) and Ligurian Sea (glider missions LS1 and LS2), and the associated mooring sites Lion and Azur. Seaglider SG524 'Kong' was deployed within the REP14-MED experiment, which aimed to explore methods for the rapid characterisation of the marine environment using a fleet of gliders (Onken et al. 2018). It followed a repeated cross-shelf zonal transect at latitude $39^{\circ} 51^{\prime} \mathrm{N}$, off the western coast of Sardinia in June 2014 (Table 1, Fig. 2), hereafter called Sea of Sardinia (glider mission SoS).

\subsection{Acoustic data sampling and processing procedures}

The 4 MOOSE PAM glider missions (GoL1, GoL2, LS1 and LS2) were designed for Weather Observation Through Ambient Noise (WOTAN) purposes and to optimise battery and memory usage (Cauchy et al. 2018). The Acousonde loggers were configured to record for $1 \mathrm{~min}$ every $10 \mathrm{~min}$ at a sampling frequency of $50 \mathrm{kHz}$. This setup saved battery, enabling a tenfold increase in monitoring duration (compared to continuous recording) to match the duration of the glider mission, and produced $27 \mathrm{~GB}$ of data every month. The PAM-equipped Seaglider of the SoS mis-

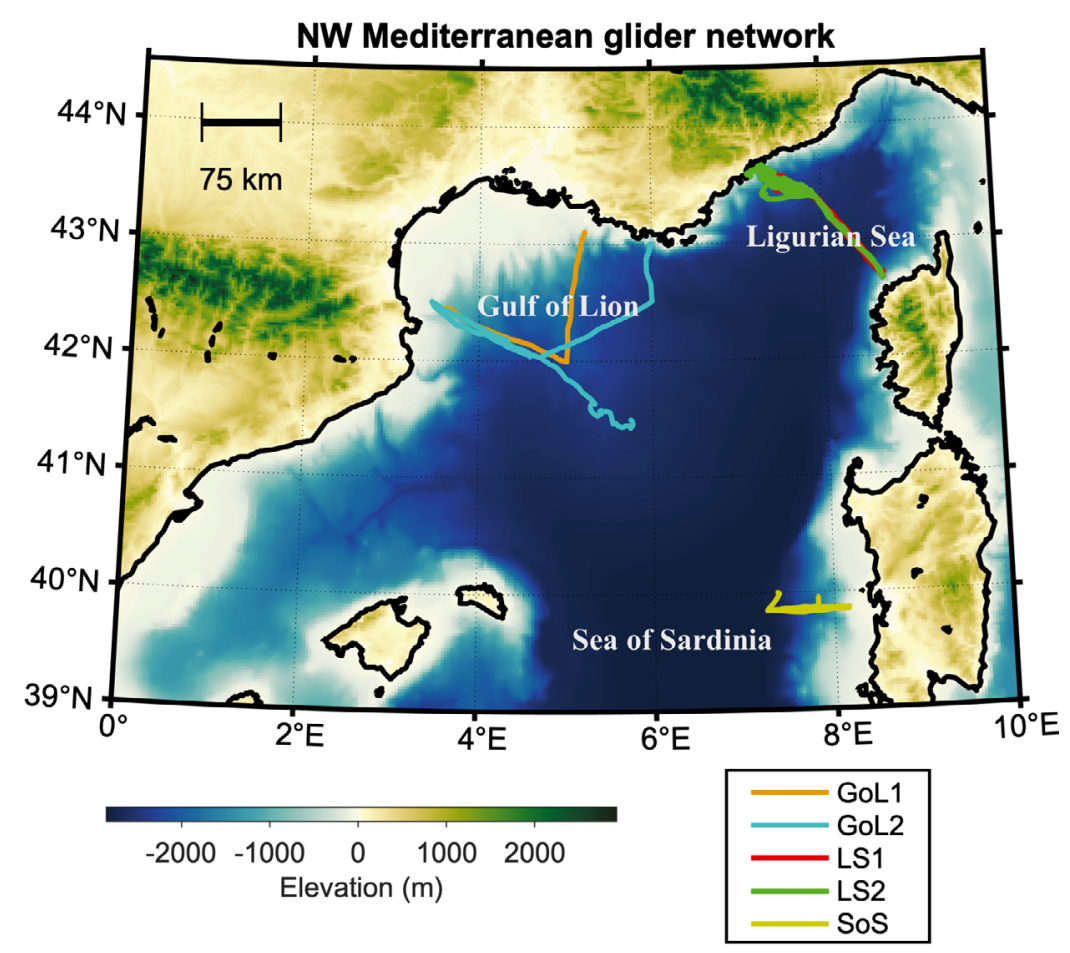

Fig. 2. Glider tracks in the north-western Mediterranean. Glider missions GoL1 and GoL2 followed predefined transects across the Gulf of Lion; LS1 and LS2 followed predefined transects across the Ligurian Sea; SoS was in the Sea of Sardinia off the Sardinian coast

Table 1. Time coverage of the glider missions (black shading) in the Gulf of Lion (blue; GoL1, GoL2), Ligurian Sea (green; LS1, LS2) and Sea of Sardinia (orange; SoS)

\begin{tabular}{|c|c|c|c|c|c|c|c|}
\hline \multirow[t]{2}{*}{ Mission } & \multirow{2}{*}{$\begin{array}{c}2012 \\
\text { Dec }\end{array}$} & \multicolumn{5}{|c|}{2013} & \multirow{2}{*}{$\begin{array}{c}2014 \\
\text { Jun }\end{array}$} \\
\hline & & Jan & Feb & Mar & Apr & May & \\
\hline GoL1 & & & & & & & \\
\hline GoL2 & & & & & & & \\
\hline LS1 & & & & & & & \\
\hline LS2 & & & & & & & \\
\hline SoS & & & & & & & \\
\hline
\end{tabular}


sion was configured to record continuously throughout the glider deployment at a sampling frequency of $125 \mathrm{kHz}$, collecting $250 \mathrm{~GB}$ of data in $14 \mathrm{~d}$.

Recordings made when the glider is sitting at the surface are contaminated by splash sounds caused by the interaction of the glider hull with the sea surface and the sensor oscillating between air and water. Water turbulence around the sensor induces flow noise at low frequencies, related to the glider's speed (Erbe et al. 2015, dos Santos et al. 2016), with no discernible effects at the sound level and frequency range of sperm whale click trains. In addition, self-noise generated by the glider comes from 4 identified behaviours: adjustment of the battery position for attitude (pitch and roll) management, rudder movements for heading adjustment (Slocum glider only), modification of the bladder volume for buoyancy management and use of the altimeter. Using the metadata provided in the glider log files, we extracted information about the noise-generating behaviours of the glider and removed the contaminated samples from the recorded acoustic data. During the missions described here, the glider spent on average $13.1 \%$ of the time at the surface (depth $<5 \mathrm{~m}$ ). When underwater (depth $>5 \mathrm{~m}$ ), the glider was quiet $96.7 \%$ of the time (Table 2). The amount of usable data, when the glider was in a quiet gliding phase, represents $84 \%$ of the total deployment time. It is worth noting that the SoS data set, collected using a Seaglider, had a lower rate of quiet gliding time $(74.8 \%)$. Frequent battery movements performed during each dive for heading adjustment were the source of this increased self-noise generation. The frequency of such manoeuvres can be modified by the pilot, depending on whether the focus is on accurate navigation, low noise emission or reduced power consumption.

The recordings were processed manually to identify sperm whale usual click trains using a graphical user interface developed in MATLAB (Fig. 3). This tool provides 2 visual representations of the acoustic signal: spectrogram (40 ms Hann window, 4 ms overlap, $100 \mathrm{~Hz}$ frequency bands) and waveform, on which to detect sperm whale usual click trains. Usual click trains are wide-band, high-intensity sounds with a regular $\sim 0.5 \mathrm{~s}$ click interval, easily identified even in the presence of other cetacean clicks (e.g. dolphin) (Fig. 3). The opportunity to listen to the audio file was

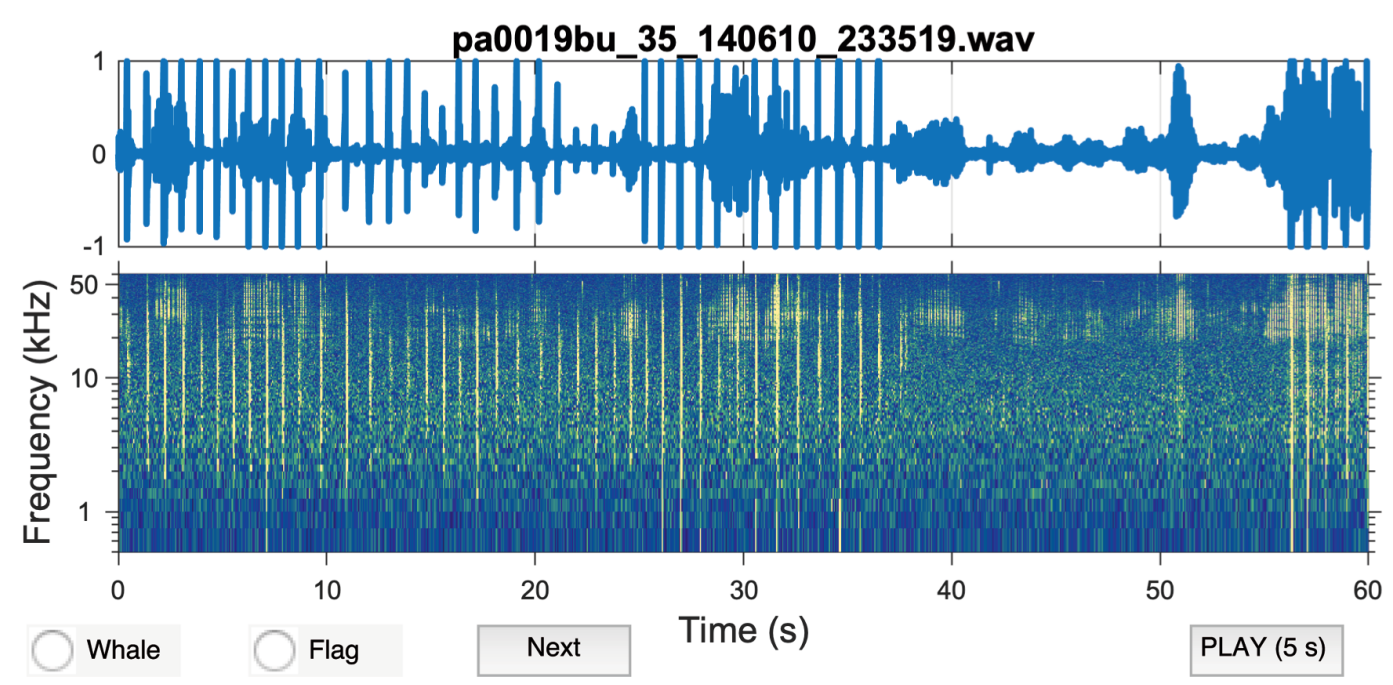

Fig. 3. Graphical user interface used for visual annotation of the acoustic files. Top panel: acoustic signal recorded as a waveform; bottom panel: spectrogram (40 ms Hann window, $4 \mathrm{~ms}$ overlap, $100 \mathrm{~Hz}$ frequency bands). The operator was given the opportunity to zoom in on both panels, and select and play a $5 \mathrm{~s}$ audio sample if needed. In this example, the wide-band highintensity sperm whale clicks trains at $\sim 0.5 \mathrm{~s}$ click intervals are easily identified even in the presence of dolphin sounds (narrower frequency band, higher frequency and click rate, higher time variability) 
also given to the operator to dispel doubt when necessary. Each file was annotated with information regarding the presence or absence of sperm whale clicks, and a flag was added in the case of identified anthropogenic noise (ship sonar, acoustic communication, acoustic trial). The whole data set was processed by the same operator. For evaluation purposes, a second operator processed a randomly selected subset of each data set, representing $20 \%$ of the glider dives, using the same tool. The classifications from the 2 operators agreed for $95 \%$ of the files (Table S1).

The files recorded between 2 successive glider surfacing phases were then regrouped as a single glider dive, annotated as containing sperm whale clicks if a dive contained at least one file with identified presence of sperm whale clicks. Finally, we defined an uninterrupted succession of glider dives with identified sperm whale presence as an encounter. For each encounter, the duration (in hours) of the event was noted, the footprint of the encounter was estimated as the largest distance between 2 glider positions during the encounter (Fig. 4) and categorisation as an aggregation or single individual was made. As it was not possible to obtain bearing information from a single hydrophone, it was difficult to differentiate sounds from several animals. We decided to limit our analysis to the identification of a single whale or an aggregation of multiple individuals. We defined an aggregation as the simultaneous detection of multiple individuals, acoustically identified as the overlap of 2 or more distinct sperm whale usual click trains.

The detection range of sperm whale echolocation clicks from moored or towed hydrophones has been estimated to be $4-20 \mathrm{~km}$ (Gannier et al. 2002, Barlow \& Taylor 2005, Hildebrand et al. 2013, André et al. 2017, Miller \& Miller 2018). In the case of glider surveys, there were no independent observation data

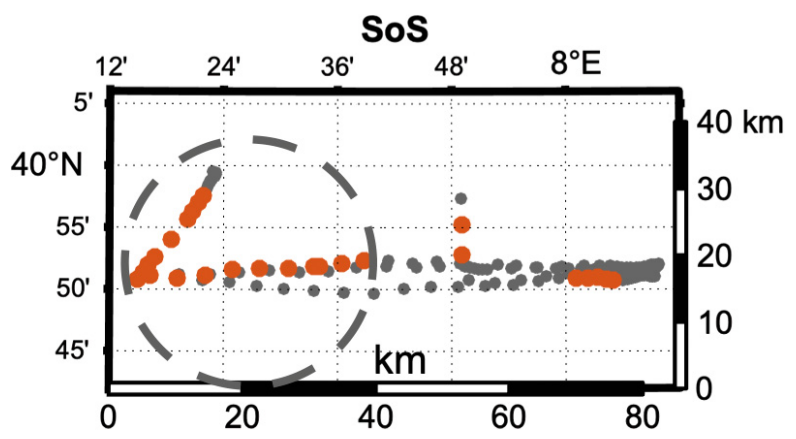

Fig. 4. Schematic of footprint estimation, using as an example the first encounter with sperm whales during glider mission SoS in the Sea of Sardinia. Glider dive locations are represented by orange dots when a sperm whale was detected, grey otherwise. The estimated footprint of the encounter is the diameter of the dashed circle: $39 \mathrm{~km}$ available from which to estimate the detection range. Limitations on weight, size and power necessitated the use of a hydrophone with reduced sensitivity, which affected the detection capacity of the system. We therefore estimated our detection range to be no greater than the observed range from moored and towed instruments. This uncertainty did not affect our observation of the spatial and temporal distribution of sperm whale detections.

Underwater sound propagation is affected by variations in sound velocity driven by temperature, salinity and pressure changes. Long-range propagation can occur in the deep sound channel, with sounds being refracted around the depth of minimum sound velocity without reflection loss on the seabed or the surface (Munk 1974). Measurements taken by the gliders provide contemporaneous knowledge of the local sound speed profile $(0-1000 \mathrm{~m})$, allowing estimation of its effects on sound propagation. We linearly extrapolated the sound speed profile to the full depth of the basin $(2300 \mathrm{~m})$ to model the refraction of acoustic rays. We modelled the propagation across depth layers of varying sound speeds for acoustic rays emitted at multiple angles by sources at depths of 300 and $1000 \mathrm{~m}$ (Jensen et al. 2011). The average sound speed profile observed during our winter surveys was characterised by a continuous positive gradient, refracting sounds towards the surface (Fig. 5). Within the estimated detection range of sperm whale echolocation clicks $(<20 \mathrm{~km})$, we expected no observable effect of recording depth on the detection range of sperm whale clicks (Fig. 5). The sound speed profile observed in June showed a strong negative gradient near the surface, a minimum around $100 \mathrm{~m}$ and then a continuous positive gradient to $1000 \mathrm{~m}$, hence refracting up and down all sound emitted within 0-1000 $\mathrm{m}$ depth and possibly extending the detection range of sperm whale clicks (Fig. 5).

\subsection{Estimation of the mixed layer depth}

Mixed layer depth is a metric commonly used in physical oceanography studies to quantify vertical homogeneity of the water column. Estimation of the mixed layer depth was made from measurements of potential temperature collected by the gliders, detecting strong temperature gradients along each vertical profile. We used a double criterion, looking for gradients greater than the potential temperature criterion, $\Delta T_{1}=0.1^{\circ} \mathrm{C}$ with the reference temperature at $10 \mathrm{~m}$ in the upper $300 \mathrm{~m}$ of the water column, and gradients greater than $\Delta T_{2}=0.01^{\circ} \mathrm{C}$ with the refer- 

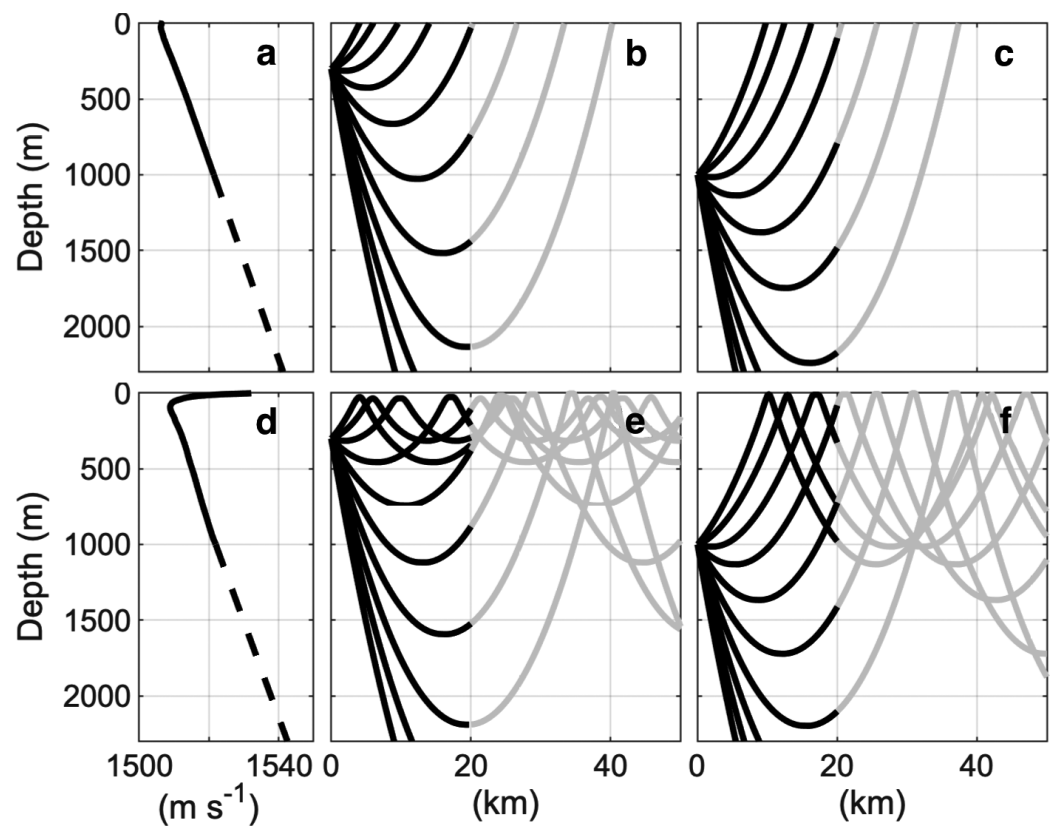

Fig. 5. Average sound velocity profiles calculated from glider temperature and salinity profiles in (a) winter and (d) summer, and associated effects on the refraction of sounds emitted at (b,e) $300 \mathrm{~m}$ and (c,f) $1000 \mathrm{~m}$. Only direct paths are shown (no reflection). Dashed line: linear extrapolation of the sound velocity profile at depth $>1000 \mathrm{~m}$. The acoustic rays are in black within the empirical sperm whale detection range $(<20 \mathrm{~km})$ and grey outside $(>20 \mathrm{~km})$

ence temperature at $300 \mathrm{~m}$ when the mixed layer depth exceeded $300 \mathrm{~m}$, to account for smaller temperature gradients in the deeper layers. This method was described in a previous study using some of the same glider data sets, focussing on deep convection events in the Gulf of Lion during 2007-2013 (Houpert et al. 2016).

\subsection{Definition of detection ratios}

Observation effort was not evenly distributed with regards to location, time of day or depth, due to specificities of the mission design and glider behaviour. The GoL and LS glider surveys were specifically designed with an increased sampling effort at the oceanographic mooring Azur and Lion locations for calibration purposes. When surveying waters shallower than $1000 \mathrm{~m}$, gliders had to interrupt their dives before reaching their usual dive depth $(1000 \mathrm{~m})$, which resulted in the number of recorded samples decreasing with depth.

To analyse the spatial distribution of sperm whale detections with regards to distance travelled along a glider track, we defined a detection ratio, corrected for uneven geographic sampling, as the ratio between the number of dives with sperm whales detected and the total number of dives in each $5 \mathrm{~km}$ distance bin. To analyse the distribution of sperm whale acoustic presence with regards to the time of day, we defined the detection ratio as the ratio between the number of files with detected sperm whale acoustic presence and the total number of samples recorded in glider quiet gliding phases in each $1 \mathrm{~h}$ bin. To analyse the distribution of sperm whale click detection with regards to measurement depth, we defined the detection ratio as the ratio between the number of files with detected sperm whale acoustic presence and the total number of files recorded in glider quiet gliding phases in each $100 \mathrm{~m}$ depth bin. We considered only the samples collected during a sperm whale encounter.

\subsection{Statistical analysis}

We used generalised additive models (GAM) to assess the statistical significance of our observations. We used R version 3.6.1 (R Core Team 2019) and the package 'geepack' (Halekoh et al. 2006) to fit binomial GAMs, with the logit link function and working independence model (Pirotta et al. 2011). For analysis of the distribution of sperm whale presence at the scale of a glider dive, we considered each encounter as an independent block. For analysis of sperm whale presence at the scale of an acoustic file (1 min), we considered each glider dive as an independent block. Statistical significance of each variable was assessed using a Wald's test.

\subsection{Glider mission SoS}

Glider mission SoS was part of the wider REP14MED experiment (Onken et al. 2018). Acoustic trials were conducted during REP14-MED, which overlapped with the glider mission in the same geographical area. Acoustic sources, emitting repeated multitonal continuous wave pulses and linear frequency modulation pulses in the $300-4000 \mathrm{~Hz}$ frequency range, were towed from 12-20 June 2014 by the NATO R/V 'Alliance' (Jiang 2016). These sounds can be detected on the glider's acoustic recordings. Our observations did not provide enough information to study the behavioural response of sperm whales to 
the acoustic trials. Such a study would require measurement of the sound level received by an individual whale, and the ability to track the individual before, during and after exposure, data typically obtained by tagging the whale with a PAM sensor (Curé et al. 2016). However, sperm whale behaviour is likely to be affected by such a nearby contemporaneous acoustic trial. Thus, we considered our sperm whale observation as corrupted from 12 June 2014 onward.

PAM glider mission SoS was reduced to $3 \mathrm{~d}$ before the start of the acoustic trial and was our only data set in the summer season and in the Sea of Sardinia. We therefore kept it separated from other glider missions in our analysis.

\section{RESULTS}

\subsection{Opportunistic observations}

The addition of PAM sensors to 5 opportunistic oceanographic glider campaigns in the north-western Mediterranean Sea allowed us to successfully detect sperm whale acoustic presence. Over the whole data set, we identified 39 sperm whale encounters, 5 of which were aggregations of 2 or more individuals. These detections were made during 129 glider dives out of 1599, resulting in 1011 audio recordings containing sperm whale clicks (Fig. 6, Tables $3 \& 4$ ). These data confirm the widespread presence of sperm whales in the area (Gannier et al. 2002, Drouot et al. 2004c, Frantzis et al. 2011, Notarbartolo-Di-Sciara 2014, Carpinelli et al. 2014). Sperm whales were encountered during 9.4 and $11.6 \%$ of glider dives during missions GoL1 and GoL2 in the Gulf of Lion, 3.9 and $7.7 \%$ of glider dives during missions LS1 and LS2 in the Ligurian Sea and 16.1\% of glider dives during missions SoS in the Sea of Sardinia (Table 3).

The duration and footprint of the encounters were highly variable (Table 4 ), depending on the mobility and speed of both the whales and the glider. At an average whale transit speed of $3 \mathrm{~km} \mathrm{~h}^{-1}$
Table 3. Number of files and dives available for analysis and with identified sperm whale click detected for glider missions GoL1, GoL2, LS1, LS2 and SoS (for locations see Fig. 1)

\begin{tabular}{|lccccc|}
\hline & GoL1 & GoL2 & LS1 & LS2 & SoS \\
\hline No. of available files & 1970 & 4350 & 6088 & 4114 & 5130 \\
Files with click detection & 55 & 214 & 54 & 102 & 586 \\
Files with click detection (\%) & 2.8 & 4.9 & 0.9 & 2.5 & 11.4 \\
No. of dives & 139 & 276 & 560 & 456 & 168 \\
Dives with click detection & 13 & 32 & 22 & 35 & 27 \\
Dives with click detection (\%) & 9.4 & 11.6 & 3.9 & 7.7 & 16.1 \\
\end{tabular}

Table 4. Duration and footprint of each sperm whale encounter for glider missions GoL1, GoL2, LS1, LS2 and SoS. Encounters with aggregations of sperm whales are in bold. Encounter ID: identification number of each encounter within a glider mission (for locations see Fig. 1)

\begin{tabular}{|c|c|c|c|c|c|c|c|c|c|c|c|c|c|}
\hline \multicolumn{2}{|c|}{ Encounter ID } & 1 & 2 & 3 & 4 & 5 & 6 & 7 & 8 & 9 & 10 & 11 & 12 \\
\hline \multirow[t]{2}{*}{ GoL1 } & Duration (h) & 5 & 2 & 11 & 1 & 1 & 1 & 3 & & & & & \\
\hline & Footprint $(\mathrm{km})$ & 5 & 2 & 1 & 1 & 1 & 1 & 1 & & & & & \\
\hline \multirow[t]{2}{*}{ GoL2 } & Duration (h) & 1 & 17 & 1 & 7 & 7 & 41 & 1 & 4 & & & & \\
\hline & Footprint $(\mathrm{km})$ & 1 & 13 & 1 & 2 & 5 & 11 & 1 & 2 & & & & \\
\hline \multirow[t]{2}{*}{ LS1 } & Duration (h) & 1 & 5 & 10 & 1 & 3 & 8 & 6 & 11 & 1 & & & \\
\hline & Footprint $(\mathrm{km})$ & 1 & 6 & 9 & 1 & 5 & 13 & 1 & 11 & 1 & & & \\
\hline \multirow[t]{2}{*}{ LS2 } & Duration (h) & 4 & 4 & 5 & 5 & 6 & 1 & 1 & 8 & 9 & 4 & 3 & 1 \\
\hline & Footprint $(\mathrm{km})$ & 6 & 5 & 5 & 5 & 4 & 1 & 1 & 5 & 9 & 6 & 2 & 1 \\
\hline \multirow[t]{2}{*}{ SoS } & Duration (h) & 53 & 6 & 8 & & & & & & & & & \\
\hline & Footprint $(\mathrm{km})$ & 39 & 6 & 8 & & & & & & & & & \\
\hline
\end{tabular}

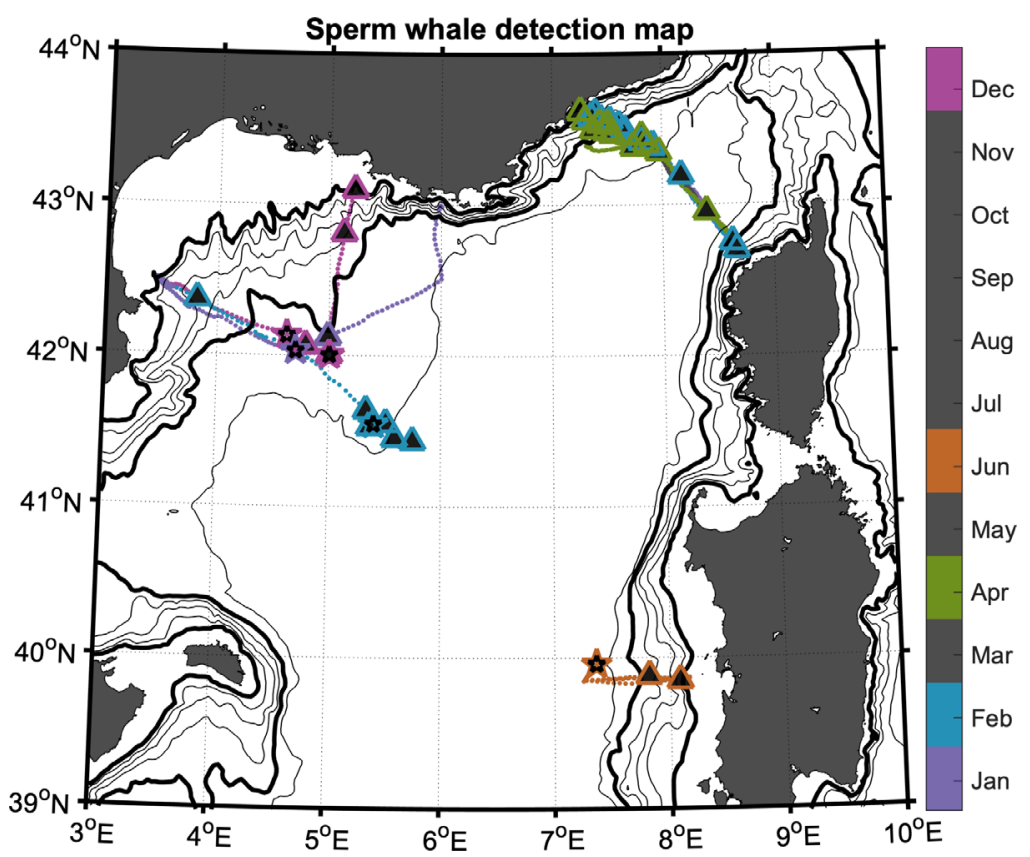

Fig. 6. Sperm whale encounters detected along the tracks of the oceanographic gliders patrolling the north-western Mediterranean Sea. Triangles: single individual detections; stars: identified sperm whale aggregations. Time of year is colour coded; months in grey had no glider observation effort. Bathymetry contours are shown from 500-2500 m with $500 \mathrm{~m}$ intervals; 200 and $2000 \mathrm{~m}$ bathymetry contours are in bold 
(Drouot et al. 2004b), a sperm whale would cross the acoustic detection range (diameter: 10-40 km) in 3-13 h, which was the case in most of our encounters with single individuals (average: $4.2 \mathrm{~h}$ ). In the case of stationary whales, a glider at a typical horizontal speed of $0.8 \mathrm{~km} \mathrm{~h}^{-1}$ would cross the detection range in $12-50 \mathrm{~h}$. Encounters with aggregations tended to last longer (average: $25.4 \mathrm{~h}$ ) than encounters with single individuals, suggesting that sperm whale aggregations were less mobile or spread out over a wider area. Our definition of aggregation includes the simultaneous presence of several isolated animals in the same area, within the detection range of the PAM glider. This configuration would necessarily explain encounters of longer duration and larger footprint. In the specific case of Encounter no. 3 of glider mission GoL1 (Table 4), the glider kept its position for $60 \mathrm{~h}$, performing 'virtual mooring' dives, and was able to detect an aggregation of sperm whales for $11 \mathrm{~h}$ with a glider footprint of only $1 \mathrm{~km}$ (Table 4). Encounter no. 1 of glider mission SoS had a footprint of $53 \mathrm{~km}$
(Table 4), larger than our estimated detection range, which suggests that the aggregation was either scattered over a wide area or was moving along with the glider. We cannot eliminate the possibility that the whales were curious about the glider and followed it.

\subsection{Repeated glider transects}

Our gliders repeatedly followed cross-shelf transects, providing information about sperm whale presence relative to the slope, defined as the closest $2000 \mathrm{~m}$ isobath. In the Gulf of Lion, glider missions GoL1 and GoL2 followed 2 cross-shelf transect lines: between the middle of the Gulf of Lion and alternatively the northern and western slopes. Our observations showed 2 modes of increased sperm whale presence around $\sim 30 \mathrm{~km}$ and $\sim 100 \mathrm{~km}$ away from the slopes (Figs. 6 to 8). In the Ligurian Sea, glider missions LS1 and LS2 followed a cross-shelf transect line between 2 slopes: France to the north and the island of Corsica
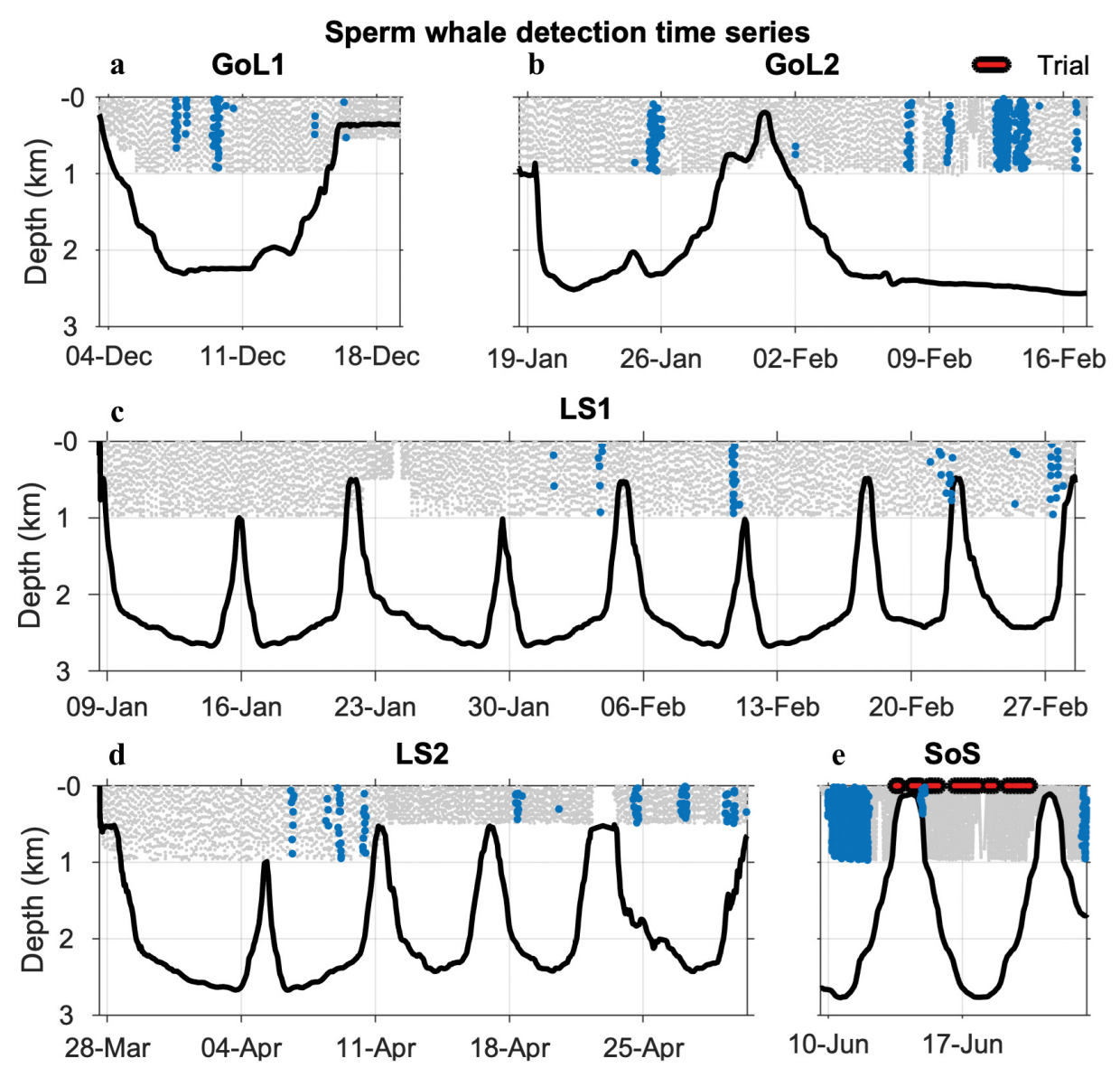

Fig. 7. Time series of sperm whale click detections along each glider section, according to the depth of the detection and bathymetry. The time and depth of each recorded file is shown in grey when no whales were detected; blue when a whale was detected. Detection of the REP14-MED acoustic trial activity is shown at the surface in red 


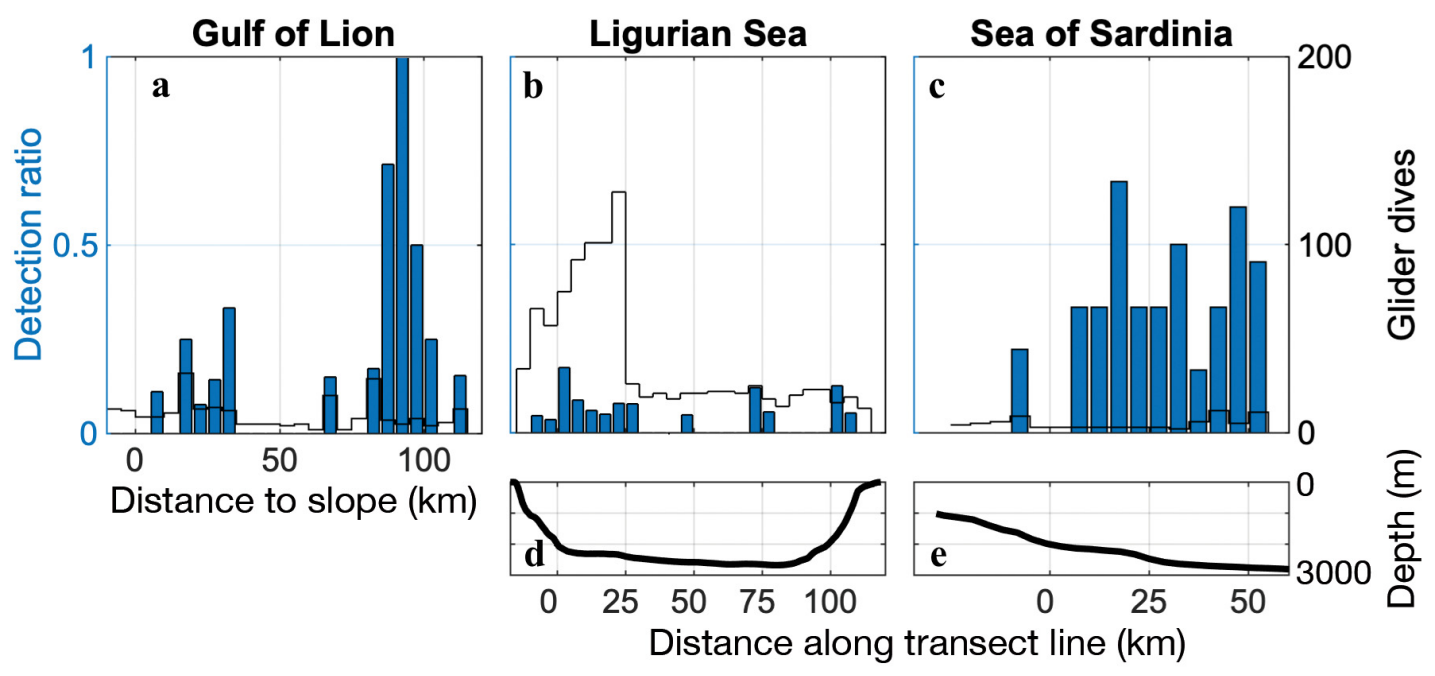

Fig. 8. Number of glider dives with acoustic recording available for analysis (black line, black vertical axis) as a function of (a) distance to the slope in the Gulf of Lion, and along the repeated glider transect line in the (b) Ligurian Sea and the (c) Sea of Sardinia. Bars (blue vertical axis): detection ratio (dives with sperm whale detection / total number of glider dives) in each 5 $\mathrm{km}$ distance bin. Bathymetry along the glider transect lines is shown for (d) the Ligurian Sea and (e) the Sea of Sardinia

to the south. Our observations suggest an increased sperm whale presence within $\sim 25 \mathrm{~km}$ of the northern slope. Sperm whales were also found in the open ocean and along the southern slope (Figs. 6 to 8). Glider mission SoS followed a cross-shelf transect between the western coast of Sardinia and the open ocean. Our observations were reduced to one long encounter with a large sperm whale aggregation, spread from the slope to the open ocean (Figs. 6 to 8). Predictions of the distribution of sperm whale presence with respect to distance to the slope and associated $p$-values for each of the 3 geographical areas studied are provided in the Supplement (Fig. S2).

\subsection{Temporal patterns}

Uninterrupted monitoring over weeks to months permits fine-scale observation of sperm whale acoustic activity. We studied the distribution of sperm whale presence with time of day for each 1 min file recorded by the gliders. In the Ligurian Sea, sperm whale clicks were detected at all times of day during both glider missions LS1 (Jan-Feb 2013) and LS2 (Apr 2013). In the Sea of Sardinia, sperm whale clicks were detected at all times of day during the glider mission (Jun 2014). In the Gulf of Lion, sperm whale acoustic activity showed a clear circadian pattern, with a decreased detection ratio at dawn for both glider missions GoL1 (Dec 2012) and GoL2 (Jan-Feb 2013) (Fig. 9). Predictions of the distribution of sperm whale presence with respect to time of day and asso- ciated p-values for each of the 3 geographical areas studied are provided in Fig. S3.

\subsection{Large-scale monitoring}

Gliders are often deployed as a coordinated fleet, offering contemporaneous observations in multiple geographic areas. During the winter 2013 season, such monitoring was possible during the overlap between glider missions GoL2 and LS1 in Jan-Feb 2013 (Table 1). Aggregations of 2 or more individuals were encountered 4 times in the Gulf of Lion (Dec 2012Feb 2013) and lone individuals were detected in the Ligurian Sea (Jan, Feb and April 2013) (Fig. 6, Table 4). It is worth noting than no sperm whales were detected during the 3 weeks sampled in January 2013.

\subsection{Collocated oceanographic measurements}

Temperature profiles collected from the gliders allowed us to estimate the mixed layer depth for each glider dive, used as an index to describe homogenisation of the water column. Observations during glider missions GoL2, LS1 and LS2 suggest an apparent increased sperm whale presence with deeper mixed layers (Fig. 10). Glider missions GoL1 and SoS only sampled stratified water masses (i.e. shallow mixed layer). Predictions of the distribution of sperm whale presence with respect to mixed layer depth obtained from the GAM and associated p-values for 


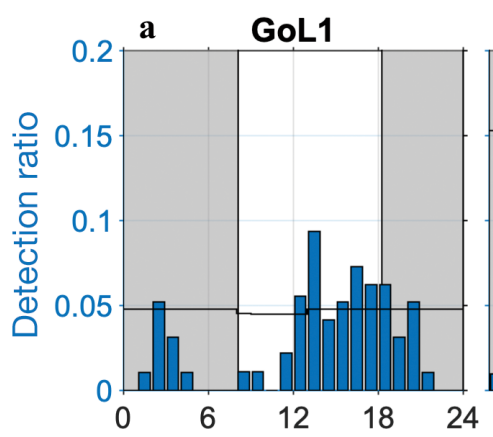

b
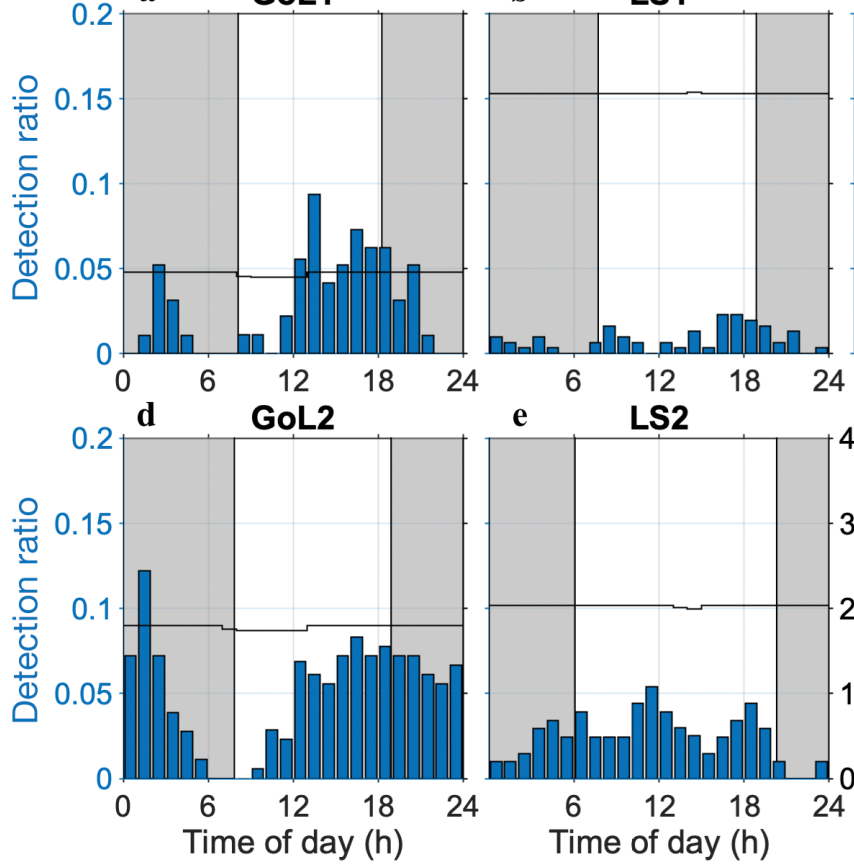

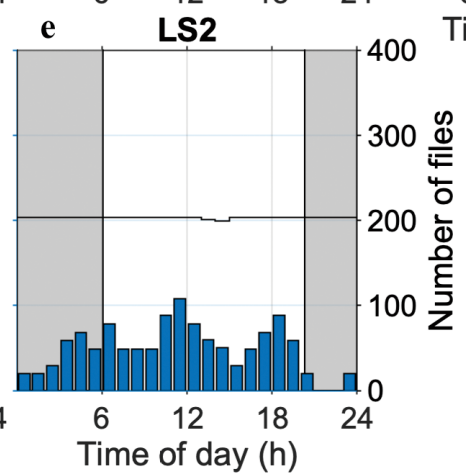

$100 \frac{\text { D }}{\frac{0}{4}}$ c Sos

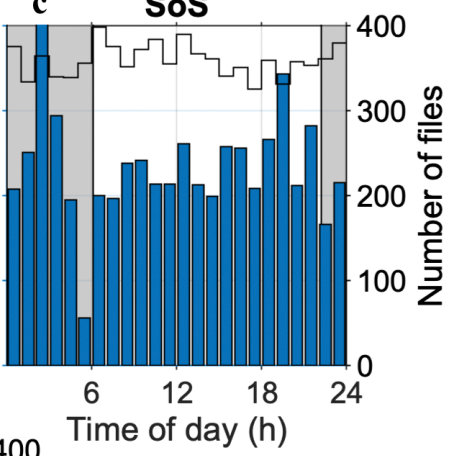

Fig. 9. Number of acoustic files available for analysis (black line, right axis) per $1 \mathrm{~h}$ bin. Bars (left axis): detection ratio (files with sperm whale detections / available files) in each $1 \mathrm{~h}$ bin. Each panel represents 1 glider mission, arranged so that each column covers 1 deployment site: (a,d) Gulf of Lion; (b,e) Ligurian Sea; (c) Sea of Sardinia
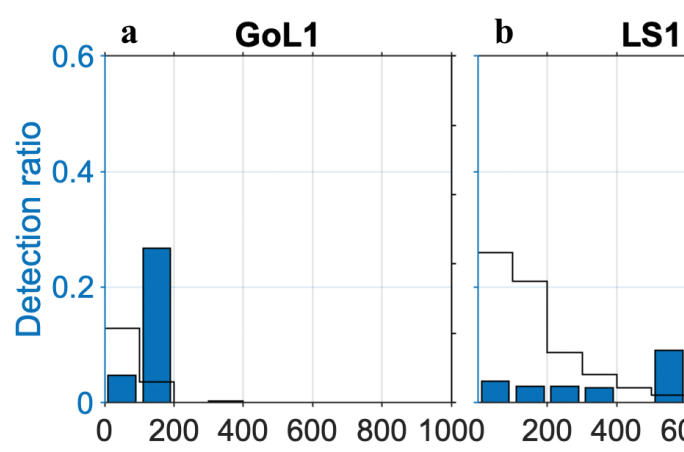

c

Sos 500

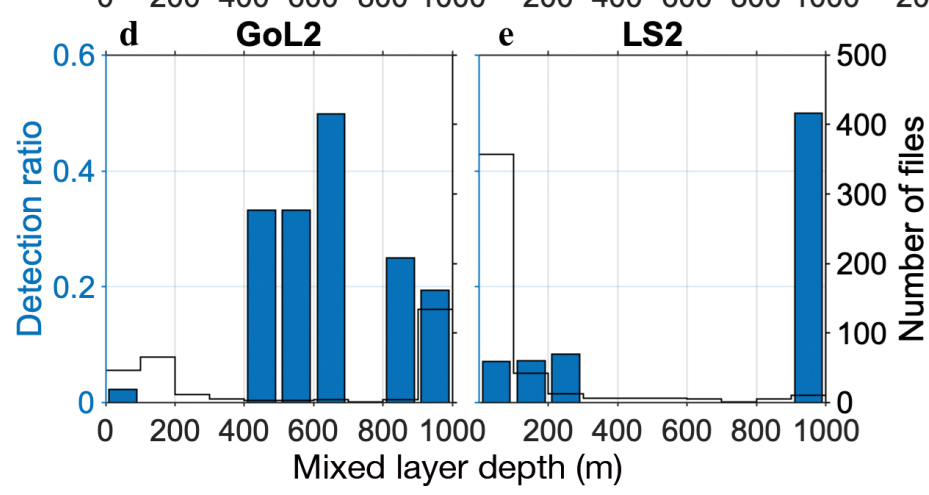

Fig. 10. Number of glider dives with acoustic recording available for analysis (black line, right axis) per $100 \mathrm{~m}$ mixed layer depth bin. Bars (left axis): detection ratio (dives with sperm whale detection / total number of glider dives) in each $100 \mathrm{~m}$ mixed layer depth bin. Each panel represents 1 glider mission, arranged so that each column covers 1 deployment site: (a,d) Gulf of Lion; (b,e) Ligurian Sea; (c) Sea of Sardinia 
each of the 3 geographical areas studied are provided in Fig. S4.

\subsection{Observations from varying depth}

The vertical profiling of the glider allowed for observation of sperm whale acoustic presence from varying depths. The distribution of sperm whale detection ratios with regards to measurement depth was highly variable among the different deployments and showed no clear signal over the whole data set (Fig. 11a). However, the SoS glider mission showed a detection ratio increasing with depth. This data set was dominated by one long duration encounter with a large aggregation (Encounter no. 1: $53 \mathrm{~h}$ ), which was also analysed separately (Fig. 11b).

\section{DISCUSSION}

\subsection{Sperm whale observation from opportunistic glider surveys}

We deployed our PAM sensors on gliders of opportunity whose missions were designed to collect oceanographic observations. We successfully detected sperm whale presence along the surveyed tracks. The PAM glider missions considered in this study offer a trial framework for PAM gliders to be used as a tool for sperm whale observations and a preview of the monitoring capabilities of purposefully designed PAM glider surveys. Oceanographic gliders have been routinely deployed in the north-western Mediterranean Sea since 2005, with a specific focus on the winter season. In the near future, similar coverage with PAM-equipped glider surveys can be adapted for sperm whale population monitoring, providing longterm, basin-wide observations. Repeated observations of sperm whale distributions along predefined glider transect lines can provide useful information about their habitat use (Verfuss et al. 2019). Intensive PAM glider observations during the winter season can fill observational gaps, such as the winter period or adverse weather conditions (Mannocci et al. 2018). Deployment of PAM gliders as a coordinated fleet can provide contemporaneous observations in multiple geographic areas to study geographical patterns.
Detection ratio

$0.3 \quad 0.6$

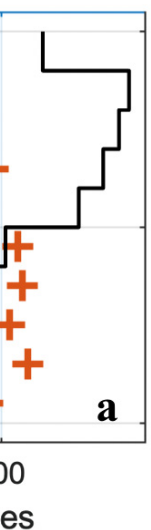

Recorded files
Detection ratio

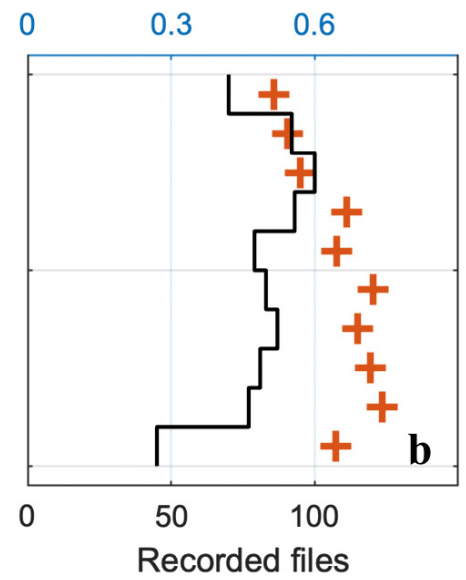

Fig. 11. Number of acoustic files available for analysis (black line, lower axis) as a function of the depth of the glider. (a) Detection ratio (files with sperm ale detection / available files) for the 4 winter (blue crosses) and summer no. 1 of glider mission SoS

\subsection{Collocated oceanographic measurements}

Oceanographic features (e.g. fronts, stratification, mixing, primary production) are a key parameter of sperm whale habitat models (Gannier \& Praca 2007, Praca \& Gannier 2008, Praca et al. 2009, Pirotta et al. 2011). PAM glider surveys enable collection of oceanographic profiles collocated along with sperm whale detection. Deep convection events, such as the one starting in February 2013 in the middle of the Gulf of Lion (Testor et al. 2018), are associated with small-scale convective plumes $(<1 \mathrm{~km}$ diameter) characterised by significant vertical velocities (up to $18 \mathrm{~cm} \mathrm{~s}^{-1}$ ) (Margirier et al. 2017). The surface signature of such events, cooling of surface waters, and the observed upwelling and downwelling (Margirier et al. 2017) are consistent with habitat-use models made using sea surface temperature data (Praca et al. 2009, Pirotta et al. 2011).

Our observations in the Gulf of Lion covered only one winter season. We are therefore unable to comment on the effect of the intensity of the mixing event on sperm whale distribution, or on inter-annual variability. Our glider missions were primarily designed to monitor deep convection events, and therefore introduce a sampling bias towards increased observation effort in deep mixed layer waters. Significance of the statistical model would benefit from correcting this bias and covering a wider variety of water column homogenisation. 


\subsection{Spatial distribution}

The spatial distribution pattern we observed during the winter 2013 season from contemporaneous glider missions in the Gulf of Lion and the Ligurian Sea suggests a geographical segregation between the Ligurian Sea, where only distant single individuals were detected, and the Gulf of Lion, where sperm whale aggregations were found. Sporadic encounters of single individuals in every area surveyed highlight sperm whale mobility in this part of the Mediterranean basin. Longer term observations are needed to better describe the complex distribution and migration patterns of the whales, such as their relatively low presence in the Ligurian Sea in January and the necessary regrouping between males and females for mating.

Cross-shelf repeated observations in the Ligurian Sea suggest possible increased sperm whale concentration along the northern slope, which was not confirmed by the statistical model. This area is a wellknown favourable sperm whale habitat, both for its topographic (steep slopes and canyons) and hydrographic (permanent front, upwellings) features (Gannier \& Praca 2007, Laran \& Drouot-Dulau 2007).

In the Gulf of Lion, the observed patches of increased sperm whale presence were not confirmed by the statistical model. The glider observations were designed to monitor an oceanographic hotspot $\left(\sim 2500 \mathrm{~km}^{2}\right)$ of intense deep mixing events occurring in winter that are likely to favour prey availability and therefore constitute favourable sperm whale habitat. Prey availability plays a key role in sperm whale distribution, as the whales adapt their distribution and group size to the size of prey patches (Relini et al. 2000, Jaquet \& Gendron 2002, Drouot et al. 2004c, Soria et al. 2009).

\subsection{Circadian pattern}

Distribution of sperm whale click detection ratios with regards to time of day showed a significant circadian pattern $\left(\mathrm{p}=6.9 \times 10^{-7}\right)$ in the Gulf of Lion (Fig. 9). Such a clear circadian pattern may suggest an adaptation of their foraging strategy to local prey behaviour (Stanistreet et al. 2018). Tag surveys have found evidence of diurnal variations of sperm whale foraging depth linked to jumbo squid Dosidicus gigas migrating deeper during daytime in the Gulf of California (Davis et al. 2007) and warty squid Onykia ingens migrating from mid-water during daytime to the bottom during nighttime in the Kaikōura submarine canyon (New Zealand) (Guerra et al. 2017). Var- ious diurnal patterns have been observed during long-term time series from passive acoustic moorings in the north-western Mediterranean Sea. A daytime peak in sperm whale acoustic presence was reported in the north of the Gulf of Lion in all 12 months of 2012 (André et al. 2017). A seasonal shift from a constant foraging effort over day and night in summer to a nighttime peak in winter was observed in the Ligurian Sea (Giorli et al. 2016), supporting the idea that the sperm whale foraging strategy is very flexible and adapts locally to environmental characteristics and prey behaviour (Stanistreet et al. 2018).

The limited time coverage of the PAM glider missions available in each geographical location did not allow us to examine the seasonality of the observed patterns. However, the contemporaneous glider missions GoL2 and LS1 (Table 1) suggest a geographical pattern during the winter season. Further observation of circadian patterns would provide valuable information on local variations of sperm whale diet and its seasonal and interannual variability.

\subsection{Seasonal to inter-annual variations}

No sperm whales were encountered in the Ligurian Sea during the 3 wk sampled in January (Table 1, Fig. 7). While we are unable to make strong conclusions about the absence of sperm whales, this data does add to similar observations previously reported for this month in the same region (Laran \& DrouotDulau 2007). It is worth noting that the sperm whale detection range from passive acoustics can be affected by local phenomena increasing the background noise (e.g. ship traffic, storms). Glider surveys GoL1, GoL2, LS1 and LS2 were previously used in a wind speed measurement study (Cauchy et al. 2018); there were no remarkable storms in January 2013 that could explain the absence of sperm whale detections.

The time coverage of the PAM glider surveys available for this study -1 mo in the Sea of Sardinia, 3 mo in the Gulf of Lion and 4 mo in the Ligurian Sea - do not exceed the intra-seasonal scale. Long-term monitoring via successive PAM glider surveys is needed to determine how the observations we made in this study vary with the seasons and through the years.

\subsection{Depth distribution}

We found no clear dependence of the sperm whale click detection ratio on the depth of the recordings made by the glider. This result is consistent with the 
highly variable foraging depth of sperm whales, their constant click production throughout the dive and the limited influence of the sound velocity profile on the detection range of sperm whale echolocation clicks. However, in the case of the SoS mission-a long encounter with a large aggregation (Encounter no. 1: $53 \mathrm{~h}$ ) - we observed an increased detection ratio with depth of the measurement (Fig. 11b). This could be due to increased prey availability at depth, which would influence the foraging pattern of observed sperm whale aggregations. Specific analysis of such a large aggregation encounter, with measurement of the number of clicks detected with depth, may provide more information about the foraging depth, and therefore diet, of an aggregation of whales at a certain time. The data available for this study did not allow us to determine whether this observed behaviour was specific to this particular time and location, or representative of general sperm whale behaviour in summer or in this region.

\subsection{Sampling strategy}

The PAM glider sampling strategy was not optimised for sperm whale population monitoring. The speed and trajectory of our glider missions differed from the usual marine mammal survey design, introducing sampling bias that could not be corrected to estimate the sperm whale population or model its habitat. The spatial-temporal coverage of our observations was sparse, making it impossible in general to determine whether the observed patterns were geographical or seasonal and leading to large uncertainties in the statistical models. Observations from glider mission SoS in particular must be regarded with caution, as it was the only glider mission in the area occurring during a summer month (Table 1). This mission was also partially corrupted by contemporaneous acoustic trial activities occurring in the area and was reduced to 3 encounters with sperm whales: twice with single individuals and once with a large aggregation (Table 4).

\subsection{Acoustic detection}

In this study, we limited our acoustic processing effort to visual detection of sperm whale usual click trains, and to a simple classification between the presence of a single individual and the simultaneous detection of several individuals. We were only interested in the presence/absence of sperm whales during $1 \mathrm{~min}$ samples, to demonstrate the validity of using PAM gliders to collect valuable data on sperm whales.

Use of onboard data-processing systems is now possible on marine autonomous platforms, allowing for real-time transmission of the observations. Development of an adapted automatic detection/classification system for PAM glider data would also allow further investigation of each acoustic file, to extract the number of detected clicks along with the number, gender and size of individuals (Caruso et al. 2015), and to look for social interactions via detection of coda sequences.

It is worth noting that using 2 or more acoustic sensors would allow for collection of bearing information, critical for counting, identifying and tracking individuals and analysing inter-pulse interval variations (Caruso et al. 2015, Kusel et al. 2017).

\section{CONCLUSIONS}

This study demonstrated that the addition of PAM sensors to existing oceanographic glider missions, with slight mission design adjustments, provides an opportunity for sustained monitoring of the Mediterranean sperm whale subpopulation over the winter months, for which there is clear lack of crucial data for conservation. Our ability to observe the population distribution in different geographic areas of the north-western Mediterranean Sea, across the slopes and in the open ocean, highlights the complexity of the sperm whale's behaviour, foraging strategy and habitat use.

We detected isolated animals in the 3 areas monitored, both on the slopes and in the open ocean. We observed areas in the open ocean in the Gulf of Lion where sperm whales were less distant and were detected at the same time from the PAM glider. The collocated collection of oceanographic measurements allowed us to identify vertically mixed waters as possible habitat hotspots for sperm whales. Continuous day and night monitoring over several months allowed for identification of a circadian pattern in sperm whale acoustic presence in the Gulf of Lion, possibly linked to a specific diet or prey availability patterns.

The use of PAM sensors can expand the observation range of existing oceanographic infrastructure. Such sustained multi-disciplinary observations would allow for a better description of the oceanographic parameters of sperm whale preferred habitat. The opportunity for sustained, long-term monitoring of cetacean populations will improve behaviour descriptions, identification of key habitats and potentially harmful interactions with anthropic activities. 
Acknowledgements. Oceanographic data were collected and made freely available by the Coriolis project (www.coriolis .eu.org) and contributing programs. We acknowledge the staff of the French National Pool of Gliders (DT-INSU/ CNRS-CETSM/Ifremer) for the sustained glider deployments carried out in the framework of MOOSE, as well as the intensive deployments during this 2012-2013 DEWEX experiment. We thank captains, crews, scientists, engineers, technicians and students who participated in the cruises and autonomous platform deployments and piloting. Support was provided by the French "Chantier Méditerranée" MISTRALS program (HyMeX and MERMeX components), the ANR ASICSMED project (ANR 12-BS06-0003), the MOOSE long-term observatory (SOERE/AllEnvi-SNO/INSU) as well as CNES/TOSCA NOISE project. Support was also provided by the EU projects FP7 GROOM (grant agreement 284321), FP7 PERSEUS (grant agreement 287600), FP7 JERICO (grant agreement 262584), and the COST Action ES0904 "EGO" (Everyone's Gliding Observatories). We thank Kongsberg for the loan of glider Kong during the REP14-MED experiment. This research was funded by the Natural Environmental Research Council (Grant NE/N012070/1) and the Engineering and Physical Sciences Research Council, via the NEXUSS Centre of Doctoral Training in the Smart and Autonomous Observation of the Environment, and as part of the Cefas-UEA strategic alliance (Cefas Seedcorn SP002). Glider data are available through the OceanGliders initiative https://doi.org/10.17882/56509. Acoustic data and metadata represent $\sim 400 \mathrm{~GB}$. Access can be provided upon request to the authors.

\section{LITERATURE CITED}

André M, Caballé A, van der Schaar M, Solsona A and others (2017) Sperm whale long-range echolocation sounds revealed by ANTARES, a deep-sea neutrino telescope. Sci Rep 7:45517

Au WWL, Giorli G, Chen J, Copeland A and others (2014) Presence and seasonal variation of deep diving foraging odontocetes around Kauai, Hawaii using remote autonomous acoustic recorders. J Acoust Soc Am 135:521-530

Barlow J, Taylor BL (2005) Estimates of sperm whale abundance in the northeastern temperate Pacific from a combined acoustic and visual survey. Mar Mamm Sci 21: 429-445

* Baumgartner MF, Fratantoni DM (2008) Diel periodicity in both sei whale vocalization rates and the vertical migration of their copepod prey observed from ocean gliders. Limnol Oceanogr 53:2197-2209

Baumgartner MF, Fratantoni DM, Hurst TP, Brown MW, Cole TVN, Van Parijs SM, Johnson M (2013) Real-time reporting of baleen whale passive acoustic detections from ocean gliders. J Acoust Soc Am 134:1814-1823

* Boisseau O, Lacey C, Lewis T, Moscrop A, Danbolt M, McLanaghan R (2010) Encounter rates of cetaceans in the Mediterranean Sea and contiguous Atlantic area. J Mar Biol Assoc UK 90:1589-1599

Burgess WC (2010) Development of a wideband acoustic recording tag to assess the acoustic behavior of marine wildlife. Greeneridge Sciences, Santa Barbara, CA

Cañadas A, Sagarminaga R, Garcla-Tiscar S, García-Tiscar S (2002) Cetacean distribution related with depth and slope in the Mediterranean waters off southern Spain. Deep Sea Res I 49:2053-2073
Carpinelli E, Gauffier P, Verborgh P, Airoldi S and others (2014) Assessing sperm whale (Physeter macrocephalus) movements within the western Mediterranean Sea through photo-identification. Aquat Conserv 24:23-30

Carrillo M, Ritter F (2010) Increasing numbers of ship strikes in the Canary Islands: proposals for immediate action to reduce risk of vessel-whale collisions. J Cetacean Res Manag 11:131-138

Caruso F, Sciacca V, Bellia G, De Domenico E and others (2015) Size distribution of sperm whales acoustically identified during long term deep-sea monitoring in the Ionian Sea. PLOS ONE 10:e0144503

Cauchy P, Heywood KJ, Merchant ND, Queste BY, Testor P (2018) Wind speed measured from underwater gliders using passive acoustics. J Atmos Ocean Technol 35: 2305-2321

* Cazau D, Bonnel J, Jouma'a J, le Bras Y, Guinet C (2017) Measuring the marine soundscape of the Indian Ocean with southern elephant seals used as acoustic gliders of opportunity. J Atmos Ocean Technol 34:207-223

Cazau D, Bonnel J, Baumgartner MF (2018) Wind speed estimation using acoustic underwater glider in a nearshore marine environment. IEEE Trans Geosci Remote Sens 57:2097-2106

* Curé C, Isojunno S, Visser F, Wensveen PJ and others (2016) Biological significance of sperm whale responses to sonar: comparison with anti-predator responses. Endang Species Res 31:89-102

* Davis RW, Jaquet N, Gendron D, Markaida U, Bazzino G, Gilly W (2007) Diving behavior of sperm whales in relation to behavior of a major prey species, the jumbo squid, in the Gulf of California, Mexico. Mar Ecol Prog Ser 333: 291-302

de Stephanis R, Giménez J, Carpinelli E, Gutierrez-Exposito C, Cañadas A (2013) As main meal for sperm whales: plastics debris. Mar Pollut Bull 69:206-214

* dos Santos FA, São Thiago PM, de Oliveira ALS, Barmak R, Lima JAM, de Almeida FG, Paula TP (2016) Investigating flow noise on underwater gliders acoustic data. J Acoust Soc Am 140:3409

Drouot V, Berube M, Gannier A, Goold JC, Reid RJ, Palsboll PJ (2004a) A note on genetic isolation of Mediterranean sperm whales (Physeter macrocephalus) suggested by mitochondrial DNA. J Cetacean Res Manag 6:29-32

Drouot V, Gannier A, Goold JC (2004b) Diving and feeding behaviour of sperm whales (Physeter macrocephalus) in the northwestern Mediterranean Sea. Aquatic Mamm 30:419-426

Drouot V, Gannier A, Goold JC (2004c) Summer social distribution of sperm whales (Physeter macrocephalus) in the Mediterranean Sea. J Mar Biol Assoc UK 84:675-680

Engelhaupt D, Rus Hoelzel A, Nicholson C, Frantzis A and others (2009) Female philopatry in coastal basins and male dispersion across the North Atlantic in a highly mobile marine species, the sperm whale (Physeter macrocephalus). Mol Ecol 18:4193-4205

Ferbe C, Verma A, McCauley R, Gavrilov A, Parnum I (2015) The marine soundscape of the Perth Canyon. Prog Oceanogr 137:38-51

Frantzis A, Alexiadou P, Paximadis G, Politi E, Gannier A, Corsini-Foka M (2003) Current knowledge of the cetacean fauna of the Greek Seas. J Cetacean Res Manag 5:219-232

Frantzis A, Airoldi S, Notarbartolo-di-Sciara G, Johnson C, Mazzariol S (2011) Inter-basin movements of Mediter- 
ranean sperm whales provide insight into their population structure and conservation. Deep Sea Res I 58:454-459

Frantzis A, Alexiadou P, Gkikopoulou KC (2014) Sperm whale occurrence, site fidelity and population structure along the Hellenic Trench (Greece, Mediterranean Sea). Aquat Conserv 24:83-102

Frantzis A, Leaper R, Alexiadou P, Prospathopoulos A, Lekkas D (2019) Shipping routes through core habitat of endangered sperm whales along the Hellenic Trench, Greece: Can we reduce collision risks? PLOS ONE 14: e0212016

Gannier A, Praca E (2007) SST fronts and the summer sperm whale distribution in the north-west Mediterranean Sea. J Mar Biol Assoc UK 87:187-193

Gannier A, Drouot V, Goold JC (2002) Distribution and relative abundance of sperm whales in the Mediterranean Sea. Mar Ecol Prog Ser 243:281-293

Giorli G, Au WWL, Neuheimer A (2016) Differences in foraging activity of deep sea diving odontocetes in the Ligurian Sea as determined by passive acoustic recorders. Deep Sea Res I 107:1-8

Gordon J, Leaper R, Hartley FG, Chappell O (1992) Effects of whale-watching vessels on the surface and underwater acoustic behaviour of sperm whales off Kaikoura, New Zealand. Science \& Research Series No. 52. Department of Conservation, Wellington

* Guerra M, Hickmott L, van der Hoop J, Rayment W, Leunissen E, Slooten E, Moore M (2017) Diverse foraging strategies by a marine top predator: sperm whales exploit pelagic and demersal habitats in the Kaikoura submarine canyon. Deep Sea Res I 128:98-108

Halekoh U, Højsgaard S, Yan J (2006) The R package geepack for generalized estimating equations. J Stat Softw 15:1-11

Hildebrand JA, Gentes ZE, Johnson SC, Frasier KE, Merkens K, Thayre BJ, Wiggins SM (2013) Acoustic monitoring of cetaceans in the northern Gulf of Mexico using wave gliders equipped with high-frequency acoustic recording packages. Tech Memo No. 539. Scripps Institution of Oceanography, San Diego, CA

Houpert L, Durrieu de Madron X, Testor P, Bosse A and others (2016) Observations of open-ocean deep convection in the northwestern Mediterranean Sea: seasonal and interannual variability of mixing and deep water masses for the 2007-2013 period. J Geophys Res Ocean 121: 8139-8171

Jaquet N, Gendron D (2002) Distribution and relative abundance of sperm whales in relation to key environmental features, squid landings and the distribution of other cetacean species in the Gulf of California, Mexico. Mar Biol 141:591-601

Jensen FB, Kuperman WA, Porter MB, Schmidt H (2011) Fundamentals of ocean acoustics. In: Computational ocean acoustics. Modern acoustics and signal processing, $2^{\text {nd }}$ edn. Springer, New York, NY, p 1-64

Jiang Y (2016) Capability of the direction of arrival estimation using a 3D acoustic compact array. Memorandum report CMRE-MR-2015-021, January 2016. NATO unclassified. Science and Technology Organization - Centre for Maritime Research and Experimentation (STO-CMRE), La Spezia

Klinck H, Mellinger DK, Klinck K, Bogue NM and others (2012) Near-real-time acoustic monitoring of beaked whales and other cetaceans using a Seaglider ${ }^{\mathrm{TM}}$. PLOS ONE 7:e36128
Kusel ET, Munoz T, Siderius M, Mellinger DK, Heimlich S (2017) Marine mammal tracks from two-hydrophone acoustic recordings made with a glider. Ocean Sci 13: 273-288

K Laran S, Drouot-Dulau V (2007) Seasonal variation of striped dolphins, fin-and sperm whales' abundance in the Ligurian Sea (Mediterranean Sea). J Mar Biol Assoc UK 87 : 345-352

Lewis T, Boisseau O, McLanaghan R, Moscrop A and others (2018) Abundance estimates for sperm whales in the Mediterranean Sea from acoustic line-transect surveys. J Cetacean Res Manag 18:103-117

* Madsen PT, Payne R, Kristiansen NU, Wahlberg M, Kerr I, Møhl B (2002) Sperm whale sound production studied with ultrasound time/depth-recording tags. J Exp Biol 205:1899-1906

*Mannocci L, Roberts JJ, Halpin PN, Authier M and others (2018) Assessing cetacean surveys throughout the Mediterranean Sea: a gap analysis in environmental space. Sci Rep 8:3126

* Margirier F, Bosse A, Testor P, L'Hévéder B, Mortier L, Smeed D (2017) Characterization of convective plumes associated with oceanic deep convection in the northwestern Mediterranean from high-resolution in situ data collected by gliders. J Geophys Res Oceans 122:9814-9826

Matsumoto H, Haxel J, Turpin A, Fregosi S and others (2015) Simultaneous operation of mobile acoustic recording systems off the Washington coast for cetacean studies. In: Proc Oceans 2015 - MTS/IEEE, Washington, DC, p 1-7

* Mellinger DK (2007) An overview of fixed passive acoustic observation methods for cetaceans. Oceanography (Wash DC) 20:36-45

*Miller BS, Miller EJ (2018) The seasonal occupancy and diel behaviour of Antarctic sperm whales revealed by acoustic monitoring. Sci Rep 8:5429 1

* Miller PJO, Johnson MP, Tyack PL (2004) Sperm whale behaviour indicates the use of echolocation click buzzes 'creaks' in prey capture. Proc R Soc B 271:2239-2247

* Møhl B, Wahlberg M, Madsen PT, Miller LA, Surlykke A (2000) Sperm whale clicks: directionality and source level revisited. J Acoust Soc Am 107:638-648

* Møhl B, Wahlberg M, Madsen PT, Heerfordt A, Lund A (2003) The monopulsed nature of sperm whale clicks. J Acoust Soc Am 114:1143-1154

* Moore SE, Howe BM, Stafford KM, Boyd ML (2007) Including whale call detection in standard ocean measurements: application of acoustic seagliders. Mar Technol Soc J 41:53-57

Munk WH (1974) Sound channel in an exponentially stratified ocean, with application to SOFAR. J Acoust Soc Am 55:220-226

Notarbartolo di Sciara G (1990) A note on the cetacean incidental catch in the Italian driftnet swordfish fishery, 1986-1988. Rep Int Whaling Comm 40:459-460

*Notarbartolo-Di-Sciara G (2014) Sperm whales, Physeter macrocephalus, in the Mediterranean Sea: a summary of status, threats, and conservation recommendations. Aquat Conserv 24:4-10

Notarbartolo di Sciara G, Bearzi G, Canadas A, Frantzis A (2004) High mortality of sperm whales in the north-western Mediterranean, 1971-2003. Paper SC/56/BC10 submitted to the Scientific Committee of the International Whaling Commission, Sorrento

* Notarbartolo-di-Sciara G, Agardy T, Hyrenbach D, Scovazzi $T$, Van Klaveren P (2008) The Pelagos sanctuary for 
Mediterranean marine mammals. Aquat Conserv 18: 367-391

Notarbartolo di Sciara G, Frantzis A, Bearzi G, Reeves R (2012) Physeter macrocephalus (Mediterranean subpopulation). The IUCN Red List of Threatened Species 2012:e.T16370739A16370477. https://dx.doi.org/10.2305/ IUCN.UK.2012-1.RLTS.T16370739A16370477.en (accessed 13 July 2020)

Nott BJ (2015) Long-endurance maritime surveillance with ocean glider networks. MSc thesis, Naval Postgraduate School, Monterey, CA

Onken R, Fiekas HV, Beguery L, Borrione I and others (2018) High-resolution observations in the western Mediterranean Sea: the REP14-MED experiment. Ocean Sci 14: 321-335

Pace DS, Mussi B, Gordon JCD, Würtz M (2014) Foreword. Aquat Conserv Mar Freshw Ecosyst 24:1-3

Pavan G, La Manna G, Zardin F, Internullo E and others (2008) Short term and long term bioacoustic monitoring of the marine environment. Results from NEMO ONDE experiment and way ahead. In: Frommolt KH, Bardeli R, Clausen (eds) Computational bioacoustics for assessing biodiversity. Proceedings of the International Expert meeting on IT-based detection of bioacoustical patterns. Federal Agency for Nature Conservation, Bonn, p 7-14

Pirotta E, Matthiopoulos J, MacKenzie M, Scott-Hayward L, Rendell L (2011) Modelling sperm whale habitat preference: a novel approach combining transect and follow data. Mar Ecol Prog Ser 436:257-272

Pirotta E, Brotons JM, Cerdà M, Bakkers S, Rendell LE (2019) Multi-scale analysis reveals changing distribution patterns and the influence of social structure on the habitat use of an endangered marine predator, the sperm whale Physeter macrocephalus in the Western Mediterranean Sea. Deep Sea Res I 155:103169

Praca E, Gannier A (2008) Ecological niches of three teuthophageous odontocetes in the northwestern Mediterranean Sea. Ocean Sci 4:49-59

Praca E, Gannier A, Das K, Laran S (2009) Modelling the habitat suitability of cetaceans: example of the sperm whale in the northwestern Mediterranean Sea. Deep Sea Res I 56:648-657

R Core Team (2019) R: a language and environment for statistical computing. R Foundation for Statistical Computing, Vienna

Relini G, Relini M, Montanari M (2000) An offshore buoy as a small artificial island and a fish-aggregating device (FAD) in the Mediterranean. Hydrobiologia 440:65-80

Rendell L, Frantzis A (2016) Mediterranean sperm whales, Physeter macrocephalus. Adv Mar Biol 75:37-74

Rudnick DL (2016) Ocean research enabled by underwater gliders. Annu Rev Mar Sci 8:519-541

Samaran F, Adam O, Guinet C (2010) Detection range modeling of blue whale calls in southwestern Indian Ocean. Appl Acoust 71:1099-1106

Editorial responsibility: Ana Cañadas, Durham, NC, USA
Soria M, Dagorn L, Potin G, Fréon P (2009) First field-based experiment supporting the meeting point hypothesis for schooling in pelagic fish. Anim Behav 78:1441-1446

Stanistreet JE, Nowacek DP, Bell JT, Cholewiak DM and others (2018) Spatial and seasonal patterns in acoustic detections of sperm whales Physeter macrocephalus along the continental slope in the western North Atlantic Ocean. Endang Species Res 35:1-13

Testor P, Meyers G, Pattiaratchi C, Bachmeyer R and others (2010) Gliders as a component of future observing systems. In: Hall J, Harrison DE, Stammer D (eds) Proc OceanObs'09: sustained ocean observations and information for society. ESA Publication WPP-306, p 961-978

Testor P, Bosse A, Houpert L, Margirier F and others (2018) Multiscale observations of deep convection in the northwestern Mediterranean Sea during winter 2012-2013 using multiple platforms. J Geophys Res Oceans 123: 1745-1776

*Van Parijs SM, Clark CW, Sousa-Lima RS, Parks SE, Rankin S, Risch D, Van Opzeeland IC (2009) Management and research applications of real-time and archival passive acoustic sensors over varying temporal and spatial scales. Mar Ecol Prog Ser 395:21-36

*Verfuss UK, Aniceto AS, Harris DV, Gillespie D and others (2019) A review of unmanned vehicles for the detection and monitoring of marine fauna. Mar Pollut Bull 140: $17-29$

Virgili A, Authier M, Boisseau O, Cañadas A and others (2019) Combining multiple visual surveys to model the habitat of deep-diving cetaceans at the basin scale. Glob Ecol Biogeogr 28:300-314

WWahlberg M (2002) The acoustic behaviour of diving sperm whales observed with a hydrophone array. J Exp Mar Biol Ecol 281:53-62

WWatwood SL, Miller PJO, Johnson M, Madsen PT, Tyack PL (2006) Deep-diving foraging behaviour of sperm whales (Physeter macrocephalus). J Anim Ecol 75:814-825

*Weilgart LS, Whitehead H (1988) Distinctive vocalizations from mature male sperm whales (Physeter macrocephalus). Can J Zool 66:1931-1937

*Weilgart LS, Whitehead H (1993) Coda communication by sperm whales (Physeter macrocephalus) off the Galapagos Islands. Can J Zool 71:744-752

*Weir CR (2008) Overt responses of humpback whales (Megaptera novaeangliae), sperm whales (Physeter macrocephalus), and Atlantic spotted dolphins (Stenella frontalis) to seismic exploration off Angola. Aquat Mamm 34:71-83

Whitehead H (2003) Sperm whales: social evolution in the ocean. University of Chicago Press, Chicago, IL

* Zimmer WMX, Tyack PL, Johnson MP, Madsen PT (2005) Three-dimensional beam pattern of regular sperm whale clicks confirms bent-horn hypothesis. J Acoust Soc Am 117:1473-1485

Submitted: July 29, 2019; Accepted: June 3, 2020

Proofs received from author(s): July 14, 2020 